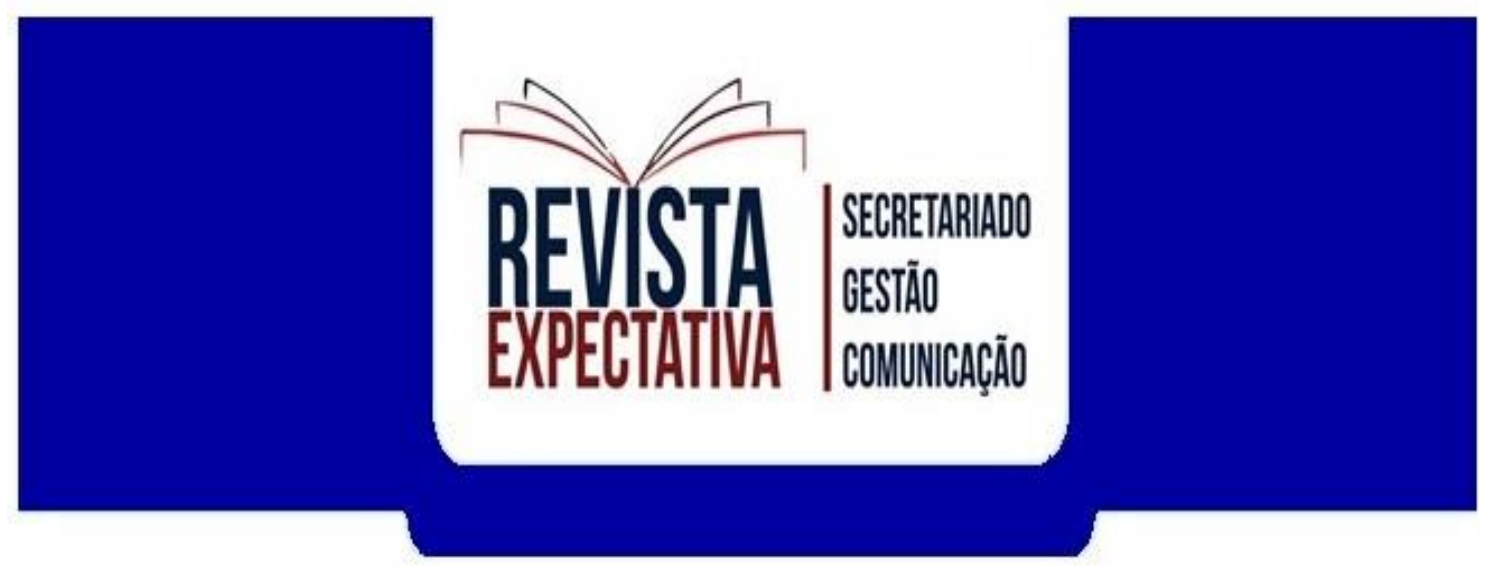

\title{
CERIMONIAL E PROTOCOLO: UM ESTUDO NO CAMPUS IV DA UFPB
}

Francisca Janete da Silva Adelino ${ }^{1}$, Elijarlyson José da Silva Barros²

Resumo: Nesta investigação, analisam-se os procedimentos protocolares utilizados nos eventos em comemoração aos dez anos do Campus IV - UFPB, a partir das regras estabelecidas pelo cerimonial público. Tem-se como objetivos específicos: observar se a composição da mesa de honra, a execução do Hino Nacional Brasileiro e a ordem de pronunciamentos foram realizados em conformidade com o Decreto Federal 70.274/1972; verificar a ordem de precedência entre as Bandeiras, a partir dos critérios estabelecidos pelo referido Decreto; analisar, a partir da visão da equipe do cerimonial, de que forma os conteúdos estudados na disciplina de Cerimonial, Protocolo e Etiqueta Empresarial contribuíram com o trabalho desempenhado nos eventos em comemoração aos 10 anos do Campus IV e analisar a formação do profissional de secretariado na condução do cerimonial universitário. O estudo adota uma abordagem qualitativa, método dedutivo, tipo descritiva e de natureza aplicada. Assim, foi realizada uma entrevista semiestruturada com um professor, dois profissionais de Secretariado e dois alunos do curso de Secretariado Executivo da UFPB. Conclui-se a partir das informações obtidas, que as regras apontadas pelo Decreto 70.274/1972, não foram aplicadas em conformidade com as regras do cerimonial público. Além disso, percebeu-se que os conhecimentos adquiridos na disciplina Cerimonial, Protocolo e Etiqueta Empresarial, auxiliaram os entrevistados para a realização dos eventos analisados, identificando o conhecimento quanto às regras gerais do cerimonial público, ressaltando assim, a prática dessas atividades pelo profissional de Secretariado na UFPB.

\footnotetext{
1 Professora doutora do Departamento de Ciências Sociais Aplicadas do curso de Secretariado Executivo da UFPB. https://orcid.org/0000-0002-3804-8507

2 Bacharel em Secretariado Executivo Bilíngue pela Universidade Federal da Paraíba. https://orcid.org/0000-0003-4073-5776
}

Editor: Cezar Roberto Versa

Recebido em: 07/12/2019 - Revisado em: 05/03/2020 - Aprovado em: 08/04/2020 
Palavras-chave: Cerimonial Público. Cerimonial Universitário. Profissional de Secretariado Executivo.

\begin{abstract}
In this investigation are analyzed the protocol procedures used in the events commemorating the ten years of Campus IV - UFPB, starting from the rules established by the public ceremonial. Are the specific objectives: observe if the composition of the Bureau, the execution of the Brazilian national anthem and the order of statements have been made in accordance with the Federal Decree 70,274 ; check the order of precedence between the flags, from the criteria established by Decree 70,274/1972; analyze, from the ceremonial team vision, how the content studied in the discipline of ceremonial, Protocol and Business Etiquette contributed the work played in events in celebration of 10 years of Campus IV and analyze the formation of professional secretariat in conducting the ceremony. The study used a qualitative approach, deductive, descriptive type method and applied in nature. Thus, a semi-structured interview with a teacher, two professionals of Secretariat and two pupils of the course of Executive Secretariat of UFPB. It is concluded from the information obtained that the rules indicated by Decree 70.274 / 72 were not applied in accordance with the rules of the public ceremonial. In addition, it was noticed that the knowledge acquired in the Ceremonial, Protocol and Business Label discipline helped the interviewees to perform the events analyzed, identifying the knowledge about the general rules of the public ceremonial, emphasizing the practice of these activities by the professional of Secretariat at UFPB.
\end{abstract}

Keywords: Public Ceremonial. University Ceremonial. Professional Executive Secretariat.

\title{
1 INTRODUÇÃO
}

O cerimonial representa o elo norteador que designa a sequência de todas as fases de um evento, seja ele público ou privado. O Cerimonial Público abrange o cerimonial dos Poderes Executivo, Legislativo e Judiciário, pertencente às esferas federal, estadual e municipal. Inclui a este, também, o cerimonial civil e militar, sendo todos esses baseados em princípios apresentados pelo Decreto ํㅜ 70.274/1972 que trata das normas de cerimonial público.

O Cerimonial Privado é direcionado aos cerimoniais voltados aos órgãos da iniciativa privada, como entidades de classe, sindicatos, órgãos institucionais e sociais. Apesar de não existir um protocolo formal para esse tipo de cerimonial, normalmente o cerimonial público é utilizado como base para o cerimonial. Assim, conhecer os critérios que norteiam o uso do Decreto 70.274/1972, é 
fundamento que ajuda a estabelecer o espaço de autoridades constituídas fora dos poderes públicos.

Apesar do Decreto que rege as cerimônias públicas no Brasil ser da década de 1970, as regras de cerimonial e protocolo existem na sociedade desde o início dos tempos, onde os seres humanos já implantavam suas regras para seguir seus rituais e cultos, nas mais diversas ocasiões de suas vidas. Nesse contexto histórico, Velloso (1999, p. 32) afirma que "o cerimonial já era regulamentado e praticado rigidamente pelos povos, de acordo com os hábitos e costumes de cada época". Para essa autora, o cerimonial envolve questões de cultura, hábitos e costumes dos povos, uma forma de organizar seus eventos da melhor forma, de acordo com cada ocasião.

Com o interesse de contribuir com as pesquisas nessa área, neste artigo analisam-se os procedimentos protocolares utilizados nos eventos em comemoração aos dez anos do Campus IV - UFPB, a partir das regras estabelecidas pelo cerimonial público. Tem-se como objetivos específicos: observar se a composição da mesa de honra, a execução do Hino Nacional Brasileiro e a ordem de pronunciamentos foram realizados em conformidade com o Decreto Federal 70.274/1972; verificar a ordem de precedência entre as Bandeiras, a partir dos critérios estabelecidos pelo referido Decreto; analisar, a partir da visão da equipe do cerimonial, de que forma os conteúdos estudados na disciplina de Cerimonial, Protocolo e Etiqueta Empresarial contribuíram com o trabalho desempenhado nos eventos em comemoração aos 10 anos do Campus IV e analisar a formação do profissional de secretariado na condução do cerimonial universitário.

Para orientar a discussão aqui proposta, o presente artigo está dividido da seguinte forma: no primeiro tópico, encontra-se a introdução com a apresentação e abordagem do trabalho. No segundo, elencam-se os referenciais teóricos nos quais são abordados os conceitos relacionados ao cerimonial e o protocolo, algumas características das cerimônias universitárias. Ainda, no segundo tópico, abordam-se as características do profissional de Secretariado Executivo em sua formação no decorrer dos anos e suas habilidades, como também sua formação profissional como facilitador do cerimonial universitário. O terceiro traz os procedimentos metodológicos e no quarto as análises dos dados da pesquisa. 
Por fim, apresentam-se as considerações gerais apontando os principais resultados atingidos na investigação.

\section{PRESSUPOSTOS TEÓRICOS: CONSIDERAÇÕES SOBRE O CERIMONIAL UNIVERSITÁRIO, PROTOCO E O SECRETÁRIO EXECUTIVO}

Para falar sobre o cerimonial universitário, faz-se necessário, primeiramente, definir o que é cerimonial e como ele é desenvolvido. Entre os conceitos abordados, identifica-se que as definições não são distantes. Para Velloso (1999, p. 32, grifo da autora), esse tipo de cerimonial é tratado como o "conjunto de normas estabelecidas com a finalidade de ordenar, corretamente, o desenvolvimento de qualquer ato solene ou comemoração pública que necessite de formalização, ou seja: inclui procedimentos como disciplina, hierarquia [...]".

Percebe-se que a autora supracitada, traz o cerimonial como um conjunto de normas. O cerimonial em si, não se trata de simples organização de um evento, é preciso um conjunto de conhecimentos que vão desde a ordem hierárquica ao bom senso. Observa-se que o conceito de cerimonial, adotado pela autora trata das normas e regras estabelecidas através do protocolo.

Nessa mesma perspectiva, Lukower (2010), por exemplo, define o cerimonial, como a aplicação prática do protocolo, mostrando que, a cerimônia deve respeitar as regras estabelecidas. O cerimonial é um conjunto de responsabilidades, uma atividade de extrema importância, que usa do protocolo para realizar procedimentos de acordo com cada evento. Para que o cerimonial possa ser desenvolvido corretamente, primeiramente é preciso que os profissionais que o executam, tenham plenos conhecimentos do evento ao qual esteja organizando.

Contribuindo que essa discussão, Viana (1998, p.12, grifo do autor) apresenta o cerimonial como "um conjunto de formalidades específicas de um ato público, dispostas numa ordem sequencial, que envolve a utilização de indumentária própria, a ordem de precedência a ser observada, com seus elementos sígnicos e o cumprimento de um ritual”. 
Logo, compreende-se que toda organização, tem o protocolo como base e necessita de cuidados específicos para desenvolver todo o evento, seja na preparação do evento, nos convites, na divulgação, na recepção dos convidados e participantes, nas inscrições, nas vestimentas dos participantes e equipe do cerimonial, da ordem de precedência a ser usada pelo mestre de cerimônias no decorrer do evento, da ornamentação do ambiente e até mesmo no pós- evento (com a entrega de certificados e avaliação do evento).

Antes e durante o evento, o profissional de cerimonial deve ter domínio de todas as regras e normas que regem as solenidades universitárias, assim como elucida Velloso (1999, p. 27), afirmando que "O profissional de cerimonial deve conhecer, pesquisar e atualizar todas as regras e normas que regem as solenidades públicas, para que se desenvolva, em ordem, todo e qualquer evento, mesmo aquele de caráter social".

Manter-se atualizado sobre as principais responsabilidades, faz com que o profissional seja cada vez mais experiente para conduzir todos os tipos de situações dentro da cerimônia. Esses são uns dos elementos a serem respeitados pela equipe de cerimonial, para que todo o trabalho possa ser executado, cumprindo na ocasião, todo ritual do protocolo e as peculiaridades do evento. Assim também, como se espera dos profissionais que trabalham com o cerimonial, a educação, a ética, o respeito, a elegância, a disciplina, entre outros.

Contudo, de acordo com os autores mencionados, pode-se observar que o cerimonial se define no exercício prático do protocolo, em atos públicos solenes, seguindo uma sequência de rituais para organizar os momentos do evento por ordem de precedência, gerenciada pelos profissionais do cerimonial. Na sequência, serão discutidos alguns elementos fundamentais relacionados ao cerimonial universitário, uma vez que este cerimonial tem suas características específicas.

\subsection{PROTOCOLO}

Quando se fala em protocolo, imagina-se registro, regras ou comportamento. O protocolo ao qual se aborda aqui se refere ao protocolo 
utilizado em eventos públicos e que são regras específicas que devem ser seguidas. Viana (1998, p. 22) apresenta o protocolo como "[...] o conjunto de regras que estão intrinsecamente ligados à etiqueta social e que servem de prérequisitos para participação num ato público. Sob esse aspecto, o protocolo é parte importante do cerimonial". Como base importante para todo o cerimonial, o protocolo serve para orientar as ações tomadas durante os atos solenes públicos, seja, costume, regras, comportamentos, leis ou normas, como definições do protocolo, este, deve ser seguido para que a solenidade tenha suas características respeitadas e praticadas corretamente.

Lukower (2010, p. 09) afirma que o protocolo é um "conjunto de normas jurídicas, regras de comportamento, costumes e ritos de uma sociedade em que um dado momento histórico, geralmente utilizadas nos três níveis de governo (federal, estadual e municipal)". Todas as definições abordadas mostram que o protocolo é um conjunto de regras, e como são regras, estas devem ser seguidas, por isso o cerimonial deve se basear no protocolo para desenvolver a cerimônia e praticá-la conforme a ocasião e como o cerimonial universitário nasce do cerimonial público as regras aplicadas ao cerimonial universitário devem ser respeitadas da mesma forma.

\subsection{ORDEM DE PRECEDÊNCIA}

A ordem de precedência determina a ordem hierárquica de quem tem prioridade sobre outra autoridade. "Precedência significa que tem prioridade, que precede ou vai à diante, ou que está antes de uma ordem determinada. Relaciona-se ao conceito de presidir, predominar, de ocupar o primeiro lugar em um grupo de pessoas (LUZ, 2005, p. 11)".

A precedência vem acompanhando a sociedade desde o início dos tempos, isso mostra que seu uso tem se intensificado nos tempos atuais, Velloso (1999, p. 37) já dialogava sobre o princípio da precedência "A Ordem de Precedência tem sido, desde os tempos mais antigos, em todas as partes, motivo de normas escritas. Ela existe em todos os níveis da sociedade, até mesmo na família". 
São várias as ocasiões em que se utiliza da precedência, e através dela, pode-se organizar melhor a ordem a ser seguida. O Decreto Federal № 70.274, orienta a execução de cerimônias públicas e a ordem geral da precedência. A precedência é utilizada, por exemplo, no Cerimonial Universitário.

Algumas universidades utilizam regras internas para se direcionar os procedimentos do cerimonial, conforme Velloso (1999, p.38) "Poucas universidades já incorporam, no seu cotidiano, suas próprias regras de cerimonial, aprovadas geralmente, por Conselho Universitário". É comum o reitor ter precedência sobre as demais autoridades, onde, apenas em alguns casos, onde, o presidente da república ou o vice-presidente esteja presente, o reitor cede a prioridade. As universidades devem seguir o decreto $\mathrm{n}^{0} \mathbf{7 0 . 2 7 4}$, de 09 de março de 1972 como fonte principal das normas a se seguir, uma vez que o mesmo aprova as normas do cerimonial e a ordem geral de precedência (VELLOSO,1999).

Essa autora toma como base o decreto acima citado como fonte para discutir atos protocolares de cerimônias universitárias "A precedência geral é aquela estabelecida através da legislação, que rege o Cerimonial Público e a Ordem Geral de Precedência (Decreto Federal № 70.274/1972, de 9/3/72), sendo interessante salientar que ela flui obedecendo a ordem hierárquica estabelecida [...]" (VELLOSO, 1999, p. 44, grifo da autora).

Com estes pensamentos vindos de pesquisadores do cerimonial Universitário, observa-se que não há outro caminho a seguir, senão o Decreto Federal 70.264, mesmo que as universidades tenham seu próprio manual, esse decreto normalmente é levado em consideração nas tomadas de decisão, principalmente, quando a questão é a ordem de precedência.

\section{3 MESTRE DE CERIMÔNIAS}

São muitas as cobranças sobre o mestre de cerimônias, afinal, ele é uma das chaves fundamentais para que a cerimônia possa passar uma boa imagem e seus conhecimentos sobre a ordem de precedência é de extrema importância, uma vez que imprevistos acontecem e suas experiências devem ajudá-lo nas decisões. 
Segundo Velloso (1999, p. 36), "O Mestre-de-Cerimônia é o condutor do evento. A ele compete conduzir, com segurança, o evento, do início ao fim: anunciar o roteiro que foi traçado pelo Chefe do Cerimonial, em boa postura e com voz firme.". Este profissional precisa, sem dúvidas, conhecer as normas do cerimonial público, como também todos os profissionais que trabalham com eventos devem ter conhecimentos a esse respeito para diante de qualquer situação possam tomar a melhor decisão de modo consciente. Ter cuidado com a aparência, com o que vestir, ter uma boa voz e diç̧ão, também são elementos que o mestre de cerimônia precisa para desenvolver um bom trabalho. A autora comenta ainda que, quando a cerimônia é iniciada, é dever do mestre de cerimônias ficar atento a qualquer situação e junto com a equipe do cerimonial, conduzir um bom evento.

Além disso, se faz necessário atentar para o uso dos símbolos nacionais, principalmente a Bandeira e o Hino Nacional. A forma de apresentação dos símbolos nacionais estão disponíveis na Lei oㅜ 5.700, de 1 de setembro de 1971, para que sua utilização seja cumprida de forma correta. A Bandeira Nacional, para Luz, (2005, p. 35) "constitui o mais relevante símbolo de um país, devendo ser respeitada por cidadãos nacionais e estrangeiros". Por essa razão, não se pode usar esse símbolo de qualquer forma, até mesmo quando não for usada, deve ser guardada com respeito. Quando se trata de hasteamento de várias bandeiras, a do Brasil (nacional) deve ser a primeira a atingir o auge e a última a ser descida. Podendo ser usada em todos os eventos de cunho patriótico.

Nas cerimônias, os profissionais da área de evento definem o número de bandeiras que serão utilizadas, o local em que serão expostas e o tipo da cerimônia realizada, para que elas sejam organizadas de forma correta. Quando se utiliza várias bandeiras, é preciso atentar para sua organização, pois a quantidade sendo ímpar, a precedência se dará à direita da bandeira nacional, e as demais na sequência, alternando à esquerda e à direita. Caso o número de bandeiras seja par em ordem de precedência, tendo a bandeira nacional como prioridade, a próxima bandeira na ordem de precedência, ficará posicionada à esquerda, e as demais ficarão alternando à direita e à esquerda (LUZ, 2005).

O Hino Nacional, quando da sua execução, deve ser ouvido ou cantado por todos, de pé, de maneira respeitosa e com a cabeça descoberta, assim como 
manda o protocolo (VIANA, 1998). Vale ressaltar que, as pessoas que são impossibilitadas de ficarem de pé, poderão ficar conforme a necessidade. De acordo com o Decreto Federal 70.274/1972 art. 20., "A execução do Hino Nacional terá início depois que o Presidente da República houver ocupado o lugar que lhe estiver reservado, salvo nas cerimônias sujeitas a regulamentos especiais". Assim, em eventos em que o presidente da república esteja presente, o hino só poderá ser executado quando ele estiver no lugar que lhe é reservado, mostrando assim a importância das autoridades para que se execute o Hino Nacional.

\subsection{COMPOSIÇÃO DA MESA}

Em várias solenidades ou reuniões a composição da mesa é um aspecto que requer certa atenção. A mesa deve ser escolhida de acordo com o tipo do evento. O lugar, os adereços, os convidados e a forma de precedência, são detalhes que não podem passar despercebidos (LUZ, 2005). Segundo esta autora, a composição da mesa é um assunto que traz elementos específicos para sua organização até mesmo o modelo a ser utilizado merece cuidados especiais, conforme afirma Viana (1998, p. 172) "A composição de mesas para reuniões protocolares no âmbito das escolas superiores pode seguir as seguintes distribuições: mesa central para atos solenes; mesa francesa ou plena; mesa inglesa; mesa em pente [...]".

Observa-se que existem tipos e formações de mesas diferentes. A esse respeito, Luz (2005) contribui dizendo que alguns tipos de mesas, e suas características podem ser divididas em dois tipos: a mesa imperial ou clássica e a mesa presidencial, onde a mesa imperial ou clássica denomina-se uma mesa clássica, retangular ou oval, separadas com duas presidências frente a frente, podendo estar no centro dos lados ou nas pontas. A mesa Imperial ou clássica pode ser apresentada de duas formas: como mesa à francesa e mesa à inglesa, onde ambas tem suas características. À mesa a francesa, o anfitrião tem prioridade na cabeceira principal e o dono da casa ficará com a segunda presidência, já a mesa à inglesa, as presidências são situadas nas pontas, sendo indicada para reuniões menos formais. 
Para melhor organizar e determinar o lugar que as autoridades irão ocupar, um dos aspectos mais importante é o referente à hierarquia (LUKOWER, 2010). Notam-se alguns critérios que se devem respeitar durante a formação da mesa segundo o Manual do cerimonial universitário da Unesp (2008) e Lukower (2010): o lado direito é considerado superior ao lado esquerdo; quando o número de autoridades for ímpar, a de maior hierarquia ficará no centro e as demais ficarão alternando à direita e à esquerda. Quando o número de autoridades for par, imagina-se uma linha no centro da mesa e a autoridade de maior hierarquia ficará à direita da linha, ao meio da mesa, os demais, ficarão alternando à esquerda e à direita da linha.

\subsection{ORDEM DOS PRONUNCIAMENTOS}

Na maioria dos eventos, é comum que as autoridades presentes façam seu pronunciamento, e esta também deve seguir uma ordem, para Couto (2013) os pronunciamentos são realizados, em ordem inversa de precedência da composição da mesa, de acordo com o protocolo estabelecido para a ocasião, sendo o pronunciamento final realizado pela autoridade máxima da mesa. Após os pronunciamentos a parte protocolar da solenidade é dada como encerrada.

Para Weber (2014, p. 55), "A ordem dos discursos é sempre inversa à ordem de composição da mesa. Começa pelo discurso da autoridade de menor hierarquia e encerra com o discurso do anfitrião". Essa ordem é a mais seguida em eventos, salientando que o anfitrião é o último a falar, caso ele seja o presidente da mesa. Algumas universidades também usam da mesma ordem de pronunciamentos para a realização de suas cerimônias, adotando-as como regras a serem seguidas em manuais.

Considerando que a maioria das universidades segue o seu próprio manual, é interessante destacar conforme consta no art. 16 do Decreto Federal 70.274/1972, "Nos casos omissos, o Chefe do Cerimonial, quando solicitado, prestará esclarecimentos de natureza protocolar bem como determinará a colocação de autoridades e personalidades [...]". 


\subsection{O PROFISSIONAL DE SECRETARIADO EXECUTIVO BILÍNGUE DA UFPB COMO FACILITADOR DO CERIMONIAL E PROTOCOLO}

A criação do curso de Secretariado Executivo Bilíngue foi autorizada pelo Conselho Universitário da UFPB - CONSUNI/UFPB em março de 2006, e desde então vem formando profissionais para o mercado de trabalho.

Com base nas informações disponíveis no Projeto Político-Pedagógico do Curso de Secretariado Executivo Bilíngue, percebe-se a preocupação para a formação do profissional que o curso de Secretariado da UFPB, Campus IV, tem para com os seus formandos:

\footnotetext{
[...] a formação do profissional Bacharel em Secretariado Executivo Bilíngue deve contemplar as relações entre o conhecimento teórico e as exigências da prática cotidiana da profissão, preparando Secretários para exercer o seu novo papel dentro das organizações, assessorando, gerenciando, gerindo fluxo de informação, utilizando novas tecnologias, inovando, enfrentando mudanças culturais, econômicas, políticas, sociais e profissionais, com sensibilidade e lucidez para diagnosticar conflitos e resistência a mudanças, com visão empreendedora, capaz de promover novos conhecimentos e provocar mudanças.
}

As exigências na formação deste profissional como se nota acima, mostra-nos a qualidade que o curso oferece a seus profissionais ao mercado, inovando e acompanhando as mudanças do mundo atual. Assim percebe-se que a promoção dos novos conhecimentos para os profissionais de secretariado só tem aumentado, tendo em vista as grandes mudanças que o mercado de trabalho sofre no dia a dia.

\section{PERCURSO METODOLÓGICO}

Este artigo representa um recorte da monografia defendida no primeiro semestre de 2017. A abordagem adotada foi qualitativa de natureza descritiva. $O$ instrumento de coleta de dados utilizado foi a entrevista. As entrevistas foram gravadas nos dias 24 e 25 de abril de 2017 e, posteriormente, transcritas, para que nenhum detalhe fosse perdido e a análise ficasse a mais fiel possível.

O roteiro foi estruturado com tópicos que instigavam os entrevistados a discorrerem sobre a composição da mesa de honra, execução do Hino Nacional 
Brasileiro e a ordem de pronunciamentos adotada na condução dos eventos em comemoração aos dez anos do Campus IV - UFPB.

Quadro 1 - Perfil dos Entrevistados

\begin{tabular}{|c|c|c|c|}
\hline Entrevistados & Idade & Formação & Eventos \\
\hline PS01 & $\begin{array}{c}34 \\
\text { Anos }\end{array}$ & $\begin{array}{l}\text { Profissional de Secretariado } \\
\text { Executivo }\end{array}$ & $\begin{array}{l}\text { Solenidade de Encerramento } \\
\text { das Comemorações dos } 10 \\
\text { Anos do Campus IV UFPB }\end{array}$ \\
\hline PS02 & $\begin{array}{c}41 \\
\text { Anos }\end{array}$ & $\begin{array}{l}\text { Egresso do Curso de } \\
\text { Secretariado UFPB; Profissional } \\
\text { de Secretariado Executivo; } \\
\text { Profissional de Eventos }\end{array}$ & $\begin{array}{l}\text { Solenidade de Encerramento } \\
\text { das Comemorações dos } 10 \\
\text { Anos do Campus IV UFPB }\end{array}$ \\
\hline P01 & $\begin{array}{c}30 \\
\text { Anos }\end{array}$ & $\begin{array}{l}\text { Profissional de Secretariado } \\
\text { Executivo; Docente }\end{array}$ & $\begin{array}{l}\text { V Encontro de Secretariado } \\
\text { Executivo Da Paraíba }\end{array}$ \\
\hline AS01 & $\begin{array}{c}26 \\
\text { Anos }\end{array}$ & $\begin{array}{l}\text { Graduando em Secretariado } \\
\text { Executivo }\end{array}$ & $\begin{array}{l}\text { Solenidade de Abertura das } \\
\text { Comemorações dos } 10 \text { Anos do } \\
\text { Campus Iv UFPB }\end{array}$ \\
\hline AS02 & $\begin{array}{c}23 \\
\text { Anos }\end{array}$ & $\begin{array}{l}\text { Graduanda em Secretariado } \\
\text { Executivo; } \\
\text { Profissional de Eventos }\end{array}$ & $\begin{array}{l}\text { Solenidade de abertura da } \\
\text { Semana Nacional de Ciência e } \\
\text { Tecnologia }\end{array}$ \\
\hline
\end{tabular}

Fonte: Dados da pesquisa

A fim de manter o caráter confidencial da pesquisa e preservar a imagem dos entrevistados, foram criados códigos para cada grupo. Assim, AS01 e AS02 correspondem à identificação dos alunos; P01 corresponde ao professor entrevistado e PS01 e PS02 corresponde aos profissionais de secretariado.

Quadro 2 - Categorias de análise

\begin{tabular}{|l|}
\hline \multicolumn{1}{|c|}{ Categorias } \\
\hline Precedência (mesa, pronunciamentos e bandeiras) \\
\hline Hino Nacional \\
\hline Desafios encontrados pela equipe. \\
\hline Importância da formação para trabalhar com eventos; \\
\hline Profissional de Secretariado da UFPB na condução de Eventos Universitários. \\
\hline
\end{tabular}

Fonte: Dados da pesquisa

A partir da transcrição e codificação da pesquisa foram construídas as categorias de análise visando uma melhor compreensão dos dados coletados. 
Em seguida, foi feita a análise dos dados, comparando os discursos dos entrevistados com os procedimentos apresentados pelo Decreto 70.274/1972 e teóricos aqui adotados.

\section{ANÁLISE E DISCUSSÃO}

Sobre a primeira pergunta, voltada para as regras de precedência, observou-se que os entrevistados tinham conhecimento sobre o assunto, uma vez que, dos cinco sujeitos da pesquisa, quatro afirmaram domínio dessa questão.

A esse respeito, o Decreto Federal 70.274/1972 orienta a execução de cerimônias públicas e a ordem geral da precedência. Tal orientação pode ser aplicada aos diversos tipos de eventos organizados na universidade. A partir desse conhecimento é possível saber a prioridade com relação à hierarquia que cada autoridade representa na composição de uma mesa de honra e também na ordem dos pronunciamentos.

Na sequência da entrevista, foi perguntado aos entrevistados se a ordem da precedência da composição da mesa de honra estava em conformidade com o que reza o Decreto Federal 70.274/1972. Nessa questão, todos os entrevistados afirmam que a formação das mesas dos eventos que eles participaram, como organizadores, estava de acordo com o que estabelece o referido Decreto, uma vez que a ordem hierárquica dos cargos (do maior para o menor) foi obedecida.

Viana (1998) traz um ponto relacionado à formação da mesa, que é a hierarquia conforme as autoridades são chamadas para compor a mesa, ele apresenta uma relação de forma hierárquica, mostrando que a mesa é formada chamando a maior autoridade para a menor autoridade.

Para o Decreto 70.274/1972 conforme 0 art. $1^{\circ}$ e art. $2^{\circ}$ :

Art. 1으 O Presidente da República presidirá sempre a cerimônia a que comparecer. Parágrafo único. Os antigos Chefes de Estado passarão logo após o Presidente do Supremo Tribunal Federal, desde que não exerçam qualquer função pública. Neste caso, a sua precedência será determinada pela função que estiverem exercendo. 
Em se tratando da precedência, é possível perceber que a hierarquia é organizada a partir da função que a autoridade estiver exercendo, mostrando assim a importância e o respeito para com a ordem de precedência. A esse respeito, Luz (2005) mostra que nas formações das mesas conforme as precedências, o lugar de honra é à direita do anfitrião ou do ponto central de referência do lugar.

O artigo segundo do referido Decreto 70.274/1972 traz a seguinte informação: "Não comparecendo o Presidente da República, o Vice-Presidente da República presidirá a cerimônia a que estiver presente". Observa-se conforme esse documento norteador do protocolo público, que existe uma relação de hierarquia em que o presidente da república comparecendo ao evento é este que sempre presidirá os trabalhos, na ausência deste é o vice-presidente que assume o lugar de honra.

Quando questionados sobre em que momento foi executado o Hino Nacional Brasileiro, dos cinco entrevistados, quatro disseram que a execução ocorreu após a formação da mesa de honra.

De acordo com o Decreto Federal 70.274 art. 20, "A execução do Hino Nacional terá início depois que o Presidente da República houver ocupado o lugar que lhe estiver reservado, salvo nas cerimônias sujeitas a regulamentos especiais". A execução do Hino Nacional somente deve ocorrer após a maior autoridade ocupar o lugar que lhe é reservado na mesa de honra. Quatro dos cinco entrevistados apontam o momento da execução do Hino Nacional para após a formação da mesa de honra. Um dos entrevistados afirma que no evento de sua organização, a execução do Hino Nacional, aconteceu antes da formação da mesa de honra, divergindo assim do Decreto.

$\mathrm{Na}$ questão referente à ordem de precedência das bandeiras, a maioria dos eventos informados pelos entrevistados não utilizou as bandeiras, com exceção do evento o qual o entrevistado AS01 participou. Segundo AS01, a sequência das bandeiras estava incorreta: "A sequência estava errada. Colocaram a ordem das bandeiras de Mamanguape e Rio Tinto, incorretas".

Seguindo os teóricos que dão suporte a este trabalho, quando são utilizadas várias bandeiras, é preciso atentar para sua organização, pois a quantidade sendo par em ordem de precedência, tendo a bandeira nacional 
como prioridade, a próxima bandeira na ordem de precedência, ficará posicionada à esquerda, e as demais ficarão alternando à direita e à esquerda. Caso o número de bandeiras seja ímpar, a precedência vai se estabelecer à direita da bandeira nacional, e as demais na sequência, alternando à esquerda e à direita (LUZ, 2005). O decreto 70.274/1972 não obriga que as bandeiras sejam utilizadas em todos os tipos de eventos, mas recomenda sua utilização apontando algumas normas dirigindo-se à Bandeira Nacional.

Ao serem questionados sobre os pronunciamentos, os entrevistados PS01 e PS02 afirmaram que a Diretora do Centro de Ciências Aplicadas e Educação - CCAE havia conduzido os pronunciamentos em forma de homenagem, asseguraram ainda que nos outros eventos, conforme as falas dos entrevistados P01, AS01 e AS02, seguiram a ordem comum: os pronunciamentos, da menor hierarquia representada na mesa, para a maior, assim como apontam os autores Brasile e Silva (2012), Weber (2014) e Couto (2013). Não é possível identificar uma regra geral para os pronunciamentos, sempre vai depender do tipo de evento, mesmo assim alguns pesquisadores adotam uma ordem respeitando a primeira fala à pessoa de menor representação e por último a fala da maior autoridade da mesa.

Quanto aos desafios encontrados, os entrevistados apontaram alguns pontos negativos: dificuldade com a infraestrutura, não ter a quantidade de bandeiras que deveria usar, a equipe de organização pequena, sem verbas para a compra de adereços, dificuldades na construção do roteiro, atraso dos representantes do evento e alguns da mesa de honra. É necessário destacar que essas experiências contribuirão na assertividade na realização de futuras cerimônias a serem organizadas por esses profissionais.

Os pontos positivos foram: os eventos serviram de fonte de aprendizado nos desenvolvimentos de cerimônias para os entrevistados, mostrando assim, o esforço e o desenvolvimento do aprendizado da disciplina em questão. Desta forma, sempre é possível aprender durante a realização e execução de eventos, qualquer tipo de evento.

Na questão referente às dificuldades encontradas pelos entrevistados nos eventos organizados, com exceção do entrevistado PS02, os demais não tiveram problemas ou não souberam responder. O entrevistado PS02 afirma que 
houve dificuldade pelo tempo, "pois foi algo muito corrido (o planejamento) e em cima da hora", seu depoimento mostra conforme a pergunta, que por esse motivo (em fazer algo em cima da hora), ele teve dificuldades para executar as normas de protocolo e cerimonial no evento.

Tratando-se das melhorias sugeridas pelos organizadores nos eventos que organizaram, o entrevistado PS02 destaca as dificuldades referentes à equipe do cerimonial, a qual merecia ainda mais formação para o evento em que participou. O entrevistado AS01, por sua vez, aponta a forma de servir água aos representantes na mesa, já o entrevistado P01 traz que o "conhecimento das normas de precedência" merecia ser aprimorado, mostrando assim a necessidade de melhora dos pontos relacionados ao cerimonial e ao protocolo como um todo. A respeito do protocolo, é preciso sempre seguir as regras, pois conforme Viana (1998), o protocolo é a parte importante do cerimonial, no qual se devem seguir corretamente as regras, o rito, comportamento etc.

Quanto à importância da formação em secretariado para trabalhar com eventos, apenas um entrevistado não cursou a disciplina de Cerimonial, Protocolo e Etiqueta Empresarial.

Os Entrevistados PS02, AS01 e AS02 afirmam que é possível planejar e executar um cerimonial aplicando as regras protocolares na forma recomendada pelo Decreto Federal 70.274/1972. Com base em suas repostas, percebe-se que a disciplina dá suporte para esta atividade conforme se observa na resposta do entrevistado AS01 "Com certeza. A disciplina dá um suporte muito bom". A disciplina de Cerimonial Protocolo e Etiqueta Empresarial (60 horas) é ministrada no nono período do curso. Já o entrevistado P01 diz que "Não, por que a carga horária é pequena e não deu tempo de trabalhar tudo, foi pincelado algumas coisas. Vim aprender mesmo na prática”, afirmando assim que em sua formação não foi possível aprender devido à extensão vasta do assunto e que aprendeu após a prática.

Em relação à importância do estudo da disciplina para a formação do profissional de Secretariado, é possível compreender que a disciplina é capaz de despertar nos alunos o gosto pela área de eventos, conforme o entrevistado PS02 destaca: "Esta disciplina me despertou a curiosidade de trabalhar com eventos". 
Todos os entrevistados trazem pontos importantes do estudo da disciplina em questão, para o entrevistado P01 "[...] a gente vive num universo cheio de eventos, e precisamos ter este conhecimento, a gente não tem como ter um curso de secretariado sem conhecer as normas do protocolo" este entrevistado explicita não apenas a importância deste aprendizado, mas também a relevância dela para a sua profissão.

O entrevistado AS01 fala que "[...] a partir do momento que a gente tem este conhecimento, poderemos não somente se comportar de acordo, somos cobrados, mas também ficamos mais críticos para que as coisas aconteçam da forma correta, e servirá sempre para nossa vida profissional", mostrando mais uma vez a importância para a vida profissional.

Já para a entrevistada AS02 diz que: "Dentro do contexto do Campus IV, é muito importante já que os alunos de secretariado estão sendo requisitados para a execução de cerimônias dentro do campus. Para mim, a disciplina foi muito importante, pois permitiu usar a teoria e a prática para meu aperfeiçoamento. Como também poderemos utilizar estes conhecimentos em outras empresas", trazendo a experiência vivida no Campus de estudo e a prática resultando no conhecimento para o aperfeiçoamento profissional.

Percebe-se que, por meio desta questão, a reflexão dos entrevistados se relacionada ao conhecimento da disciplina, por fazer parte de um universo cheio de eventos, e que necessitamos destes conhecimentos para trabalhar de forma diferenciada no mercado, podendo contribuir em qualquer empresa e em diferentes cerimônias.

Com relação aos conteúdos trabalhados na disciplina de Cerimonial, Protocolo e Etiqueta Empresarial, e seu favorecimento para a realização dos eventos, de forma geral, considerando que o entrevistado PS01 não estudou a disciplina, afirma-se pelos demais entrevistados que a disciplina tem uma contribuição muito boa na formação dos profissionais.

Conforme o entrevistado PS02, cuja resposta foi: "Claro, que sim. Por que o que a gente aprende na disciplina é o que a gente leva de bagagem para a realização de eventos como esse", percebe-se que a disciplina proporciona aos alunos que possam desenvolver seus conhecimentos, favorecendo assim na realização das cerimônias que participaram; o entrevistado P01 diz que a 
disciplina favoreceu sim, na realização do evento, sendo mais uma confirmação positiva para o suporte que a disciplina dá ao profissional na realização dos eventos, não sendo diferente para os entrevistados AS01 onde responde que "Sem dúvidas, foi a base forte para que a gente pudesse realizar este cerimonial" e o entrevistado AS02 afirma a contribuição da disciplina para a prática: "Sim, com certeza, pois tivemos o estudo, a teoria e depois pusemos em prática".

Relacionado ao mercado de trabalho para a área de Cerimonial, Protocolo e Etiqueta, observa-se a partir das respostas dos entrevistados de forma unânime, que esta área de formação se apresenta como possibilidade para ingressar no mercado de trabalho, o entrevistado PS01 afirma que sim; já o entrevistado PS02 diz que, "Com certeza. Talvez aqui seja um mercado pequeno, mas se você vai para a capital, as oportunidades são muito maiores. E acredito que é um mercado em expansão".

Para o entrevistado P01, a área se apresenta como possibilidade de ingressar no mercado de trabalho e ainda completa dizendo que "o universo em si, ele conspira a favor dos eventos e a gente encontra no mercado de trabalho muitas empresas atuando sem capacitação prévia, então é uma ótima oportunidade". Ele aponta ainda que o mercado muitas vezes funciona com profissionais sem capacitação prévia e por serem poucos os especializados nesta área o mercado sempre abre as portas para estes profissionais, citando ainda que o universo é cheio de eventos por isso tamanha oportunidade.

O entrevistado AS01 concorda com os demais entrevistados alega que o mercado é pequeno, mas que há possibilidade de oportunidades: "Sem dúvidas, por ter poucos profissionais na área, e sempre aparecerá oportunidades", não sendo diferente dos demais, o entrevistado AS02 concorda com isso, mostrando que esse conhecimento traz o diferencial do profissional conforme sua resposta: "Sim, até por que se torna um diferencial para a área de evento".

Ao se tratar da condução de cerimônias universitárias na UFPB por profissionais de Secretariado, esta questão reflete não somente na formação dos profissionais de secretariado com relação aos conhecimentos do cerimonial universitário, mas traz também o pensamento relacionado ao conhecimento adquirido e sua competência para esta atividade. 
Por se tratar de Profissionais de Secretariado e estudantes da área, é possível identificar nas respostas que a maioria dos entrevistados acredita na aptidão para a condução de cerimônias universitárias. Os entrevistados P01 e AS01 salientam ainda a seguinte assertiva: para que o profissional de Secretariado possa realizar as cerimônias universitárias, é preciso um esforço pessoal para capacitação desta atividade. Afirma ainda o entrevistado P01 que nem tudo é passado em sala de aula.

Tratando de cerimonial e das habilidades destes profissionais para desenvolver um evento, no questionamento de ํo 8 foi apresentado algumas opções e como resposta obtivemos na maioria da resposta a letra $A$, na pergunta tinha as seguintes opções: "A) Disciplina, conhecimento sobre as regras geral de cerimonial público, elegância, respeito, bom-senso, bom gosto e simplicidade, B) Outros. Quais?, C) Não precisei utilizar nenhuma habilidade, D) Justifique sua resposta!", os entrevistados mencionaram algumas outras habilidades para completar, sobre o que foi necessário para realizar a cerimônia que organizou.

Percebe-se que, não se precisa necessariamente saber a forma da ocorrência do cerimonial, mas da necessidade de alguns conhecimentos complementares para o desenvolvimento do cerimonial de forma mais segura e assertiva. Conforme foram citadas algumas opções na pergunta feita, é possível verificar que outros elementos a mais, aparecem para completar as habilidades que foram desenvolvidas no cerimonial, dentre as citadas na letra $A$, também surgiram: resiliência, a proatividade e a inteligência intrapessoal, com enfoque nos conhecimentos sobre as regras do cerimonial público.

Quando questionados se o cerimonial e o protocolo foram realizados de acordo com o Decreto Federal 70.274/1972, apenas um dos entrevistados afirma que o cerimonial e o protocolo não foram realizados de acordo com o Decreto Federal 70.274/1972. Considerando que o referido Decreto serve para orientar as cerimônias públicas, o conhecimento do entrevistado P01 identificou a falta da aplicabilidade deste documento norteador de execução de protocolo no evento que organizou.

São diversas as atribuições destes profissionais nos eventos analisados. Para o entrevistado PS01: envio de convites, a comunicação pré-evento; o entrevistado PS02 pode coordenar o cerimonial, as atribuições do entrevistado 
P01 foram de coordenar a comunicação, comunicando com o público externo e interno de forma escrita e visual principalmente, para o entrevistado AS01. Notase que ele auxiliou o mestre de cerimônias, e prestou de suporte geral para 0 evento, já o entrevistado AS02 ficou responsável pelo gerenciamento das artes e outras atividades como é possível ver em sua resposta acima. Percebe-se que os eventos, de forma positiva, trouxeram aos entrevistados experiências que pudessem capacitá-los/aprimorá-los de alguma forma, sendo que, o objetivo maior destas atribuições, era a realização e o sucesso da cerimônia.

\section{CONSIDERAÇÕES FINAIS}

O propósito desta pesquisa foi 0 de analisar os procedimentos protocolares utilizados nos eventos em comemoração aos dez anos do Campus IV - UFPB, a partir das regras estabelecidas pelo cerimonial público. A realização deste trabalho é uma maneira de abranger novos debates e futuros trabalhos acadêmicos relacionados ao tema abordado, na perspectiva do profissional de Secretariado Executivo expandir os novos conhecimentos e reflexões sobre o cerimonial universitário como mais um de seus conhecimentos para o mercado de trabalho, trazendo para si esta bagagem que também lhes cabem.

Com a conquista de espaço que os profissionais de secretariado cada vez mais vêm adquirindo ao passar dos tempos, é interessante discutir sobre o tema abordado, uma vez que este profissional tem o conhecimento e este tema também por se tratar da comunicação não poderia passar despercebido.

No que se refere ao primeiro objetivo específico, que foi observar se a composição da mesa de honra, a execução do Hino Nacional Brasileiro e a ordem de pronunciamento foram realizados em conformidade com o Decreto Federal 70.274/1972, foi possível observar que as formações das mesas dos 4 eventos citados pelos entrevistados estavam corretas. Os entrevistados afirmaram que houve uma ordem em sua formação, respeitando a hierarquia das autoridades, usando a precedência conforme o Decreto acima citado.

Sobre a execução do Hino Nacional, foi possível perceber que todos os eventos não seguiram uma mesma ordem, podendo ser visível em uma das 
respostas o fato da execução do hino acontecer antes da formação da mesa. Verifica-se conforme as repostas dos entrevistados, que os demais seguiram a execução do Hino Nacional após a formação da mesa conforme se percebe a aplicação do Decreto citado, respeitando assim que as autoridades estejam em seus assentos; já no que diz respeito à ordem de pronunciamentos, como não existe uma regra geral definida pelo Decreto, é possível perceber que nas repostas dos entrevistados, a maioria seguiu o que a literatura recomenda, dáse primeiramente a fala a menor representação hierárquica que se encontra na mesa. Conclui-se a partir das informações obtidas, que não foram todos os elementos apontados por este objetivo específico, realizados em conformidade com as regras do cerimonial público, em que podemos atribuir esta conclusão a execução incorreta em um dos eventos.

Em relação ao segundo objetivo especifico que se propôs "verificar a ordem de precedência entre as Bandeiras, a partir dos critérios estabelecidos pelo Decreto 70.274/1972", compreende-se que, a maioria dos eventos não utilizara as bandeiras. Mas um dos entrevistados afirmou que no seu evento a ordem das bandeiras estava incorreta. Conclui-se a partir desta afirmação que a precedência em pelo menos um dos eventos em que usaram a bandeira, não estava correta.

No terceiro objetivo específico, buscou-se "analisar, a partir da visão da equipe do cerimonial, de que forma os conteúdos estudados na disciplina de Cerimonial, Protocolo e Etiqueta Empresarial contribuíram com o trabalho desempenhado nos eventos em comemoração aos 10 anos do Campus IV". A partir da análise das entrevistas foi possível identificar que os conteúdos estudados nesta disciplina contribuíram para a realização dos eventos dos quais organizaram.

O quarto e último objetivo específico foi o de "analisar, de acordo com as respostas dos nossos entrevistados, a formação do profissional de secretariado na condução do cerimonial universitário". Nesse sentido, as entrevistas foram feitas com estudantes e profissionais de Secretariado Executivo e estes fizeram parte das organizações dos eventos em comemoração aos 10 anos do campus IV UFPB, apontando os detalhes analisados tanto para com os eventos como também para formação da equipe organizadora do evento. 
Tratando-se da pergunta que também motivou esta pesquisa, reflete-se agora sobre o problema proposto a este trabalho que foi: "o cerimonial e 0 protocolo utilizados nos eventos em comemoração aos dez anos do campus IV seguiram as normas do cerimonial público estabelecidas pelo Decreto Federal no 70.274/1972?" Como o problema generaliza de forma que todos os eventos necessitariam seguir as regras do Decreto Federal para que sua reposta fosse positiva, a resposta para esta pergunta é: não. Para chegar a esta conclusão, verifica-se as seguintes questões: No que se refere ao Hino Nacional, foi possível constatar que ele não foi executado da forma correta, conforme discussão e análise dos dados; se tratando da ordem das bandeiras, também foi possível examinar que a ordem em um dos eventos não estava correta.

Conforme objetivo geral deste trabalho, foi possível analisar a partir dos objetivos específicos, (tendo como base os teóricos adotados e também o Decreto Federal 70.274/1972), os procedimentos protocolares utilizados nos eventos em comemoração aos 10 anos do Campus IV UFPB, nas composições das mesas, na execução do Hino Nacional, nas ordens das bandeiras, em todo cerimonial levantando análise também sobre a contribuição do profissional de Secretariado Executivo nestes eventos, mostrando sua formação e execução do Cerimonial Universitário na UFPB, sendo possível então, analisar e responder o problema proposto a esta investigação.

Com esta pesquisa, espera-se que a comunidade científica possa despertar o interesse para a relevância do tema, investindo em pesquisas e estudos, dando suporte às discussões sobre o tema abordado, fortalecendo assim a pesquisa secretarial local, regional e nacional.

\section{REFERÊNCIAS}

ABRÃO, A. Y. Conflitos de gerações e as competências da secretária no século XXI. In: D'ELIA, B.; AMORIM, M.; SITA, M.(Orgs.). Excelência no Secretariado: A importância da profissão nos processos decisórios como assessor e atingir resultados corporativos e pessoais com competência e qualidade.São Paulo: Editora Ser Mais,2013.

AZZOLIN, M. L. T. Cerimonial universitário: instrumento de comunicação. 2. Ed. Maringá: Eduem, 2010. 
BECHERA, E. Dicionário escolar da academia brasileira de letras: Língua Portuguesa. In: BECHERA, E. (Org). Dicionárioescolar da academia brasileira de letras: Língua Portuguesa. São Paulo: Companhia Editora Nacional, 2011.

BOGDAN, R.; BIKLEN, S. Investigação qualitativa em educação: Fundamentos, métodos e técnicas. Portugal: Porto Editora, 1994.

BRASILE, R.; SILVA, S. M. Manual Cerimonial e Protocolo para eventos da UFG. Goias: UFG, 2012.

CAMPOS, C. J. G. Metodologia Qualitativa e Método Clínico-Qualitativo: Um panorama geral de seus conceitos e fundamentos. Introdução à metodologia da pesquisa clínico-qualitativa: definições e principais características. São Paulo: 2000.

COUTO, H. P. DO. Cerimonial Universitário: Análise das cerimônias oficiais da Universidade Federal Fluminense com base nas normas protocolares. 2013. 146 f. Graduação em Turismo, UFF, Niterói, 2013.

DECRETO FEDERAL № 70.274 DE 09 DE MARÇO DE 1972. Disponível em: http://www.planalto.gov.br/ccivil_03/decreto/d70274.htm . Acesso em: 23 jan 2017.

Disponível em: http://www.ufpb.br/content/campus-do-litoral-norte-da-ufpbcomemora-dez-anos. Acesso em: 05 abril 2017.

Disponível em: http://www.ccae.ufpb.br/secretariado/contents/noticias/matrizdisciplinas-e-pre-requisitos-secretariado-executivo-2016. Acesso em: 22 mar 2017.

Disponível em: https://sigaa.ufpb.br/sigaa/ava/index.jsf. Acesso em: 08 mar 2017.

GIL, A. C. Como elaborar projetos de pesquisa. 4. ed. São Paulo: Atlas, 2002. 2008.

Métodos e Técnicas de Pesquisa Social. 6. ed. São Paulo: Atlas, 
LAKATOS, E. M.; MARCONDI, M. DE. A. Fundamentos de Metodologia

Científica. 5. ed. São Paulo: Atlas, 2003.

LEI No 7.377, DE 30 DE SETEMBRO DE 1985. Disponível em:

http://www.planalto.gov.br/ccivil_03/leis/L7377.htm. Acesso em: 15 fev2017.

LEI № 5.700, DE 1ㅇ DE SETEMBRO DE 1971.Disponível em: < http://www.planalto.gov.br/ccivil_03/Leis/L5700.htm>. Acesso em: 15 fev2017.

LINS, Augusto Estelita. Evolução do Cerimonial Brasileiro: aulas e conferências. Recife: Comunigraf, 1999.

LUKOWER, A. Cerimonial e Protocolo. 3. ed. São Paulo: Contexto, 2010.

.Cerimonial e Protocolo. 4. ed. São Paulo: Contexto, 2015.

LUZ, O. R. Cerimonial e Protocolo e Etiqueta-Introdução ao Cerimonial do Mercosul: Argentina e Brasil. São Paulo: Saraiva, 2005.

MANUAL do cerimonial da unesp. São Paulo: Unesp, 2008.

NONATO JÚNIOR, R. Epistemologia e teoria do conhecimento em secretariado executivo: a fundação das ciências da assessoria. Fortaleza: Expressão Gráfica, 2009.

PRODANOV, E. C. DE. F. Metodologia do trabalho científico: Métodos e técnicas da Pesquisa e do Trabalho Acadêmico. 2. ed. Novo Hamburgo: Feevale, 2013.

SILVA, A. B. A vivência de conflitos entre a prática gerencial e as relações em família. 2005. Tese (Doutorado em Engenharia de Produção). Universidade Federal de Santa Catarina, Florianópolis, 2005.

SILVEIRA, D. T.; CÓRDOVA, F. P. A pesquisa Científica. In: GERHARDT, T. E.; SILVEIRA, D. T. (Orgs.). Métodos de Pesquisa. Porto Alegre: Editora da UFRGS, 2009. cap. 2.

SIMBOLOS NACIONAIS. Disponível em:

www2.planalto.gov.br/acervo/símbolos-nacionais/. Acesso em: 23 jan 2017. 
UFPB. Projeto Político Pedagógico do Curso de Secretariado Executivo bilíngue, ano 2006.

VELLOSO, A. Cerimonial Universitário. Brasília: Editora Universidade de Brasília, 1999.

VIANA, F. B. Universidade: Protocolo, Rito e Cerimonial. Lúmen:1998.

WEBER, T. R. Cerimonial Universitário: Sistematização na Universidade Federal de Santa Maria. 2014. 93 f. Dissertação (Mestrado Profissional em Gestão de Organizações Públicas), Universidade Federal de Santa Maria, Santa Maria, 2014.

ZAMPIER, M. B.; ARRUDA, A. S. Manual para a elaboração de projetos de monografia. Mamanguape/PB, p. 1-16, 2011. 